\title{
Intercalation of $\mathrm{Ca}$ into a Highly Defective
}

\section{Manganese Oxide at Room Temperature}

Bob Jin Kwon ${ }^{1,2 *}$, Liang Yin ${ }^{2,3}$, Christopher J. Bartel ${ }^{2,4,5}$, Khagesh Kumar $^{6}$, Prakash Parajuli ${ }^{2,7}$, Jihyeon Gim ${ }^{1}$, Sanghyeon Kim ${ }^{1,2}$, Yimin A. Wu ${ }^{2,7}$, Robert F. Klie ${ }^{2,7}$, Saul H. Lapidus ${ }^{2,3}$, Baris Key ${ }^{1,2}$, Gerbrand Ceder ${ }^{2,4,5}$, and Jordi Cabana ${ }^{2,6^{*}}$

${ }^{1}$ Chemical Sciences and Engineering Division Argonne National Laboratory, Lemont, IL 60439, United States

${ }^{2}$ Joint Center for Energy Storage Research, Argonne National Laboratory, Lemont, IL 60439, United States

${ }^{3} \mathrm{X}$-ray Science Division, Advanced Photon Source, Argonne National Laboratory, Lemont, IL, 60439, United States

${ }^{4}$ Department of Materials Science and Engineering, UC Berkeley, Berkeley, CA, 94720, United States

${ }^{5}$ Materials Science Division, Lawrence Berkeley National Laboratory, Berkeley, CA, 94720, United States

${ }^{6}$ Department of Chemistry, University of Illinois at Chicago, Chicago, IL 60607, United States

${ }^{7}$ Department of Physics, University of Illinois at Chicago, Chicago, IL 60607, United States

\section{Corresponding Author}

*E-mail: bkwon@anl.gov, jcabana@uic.edu 

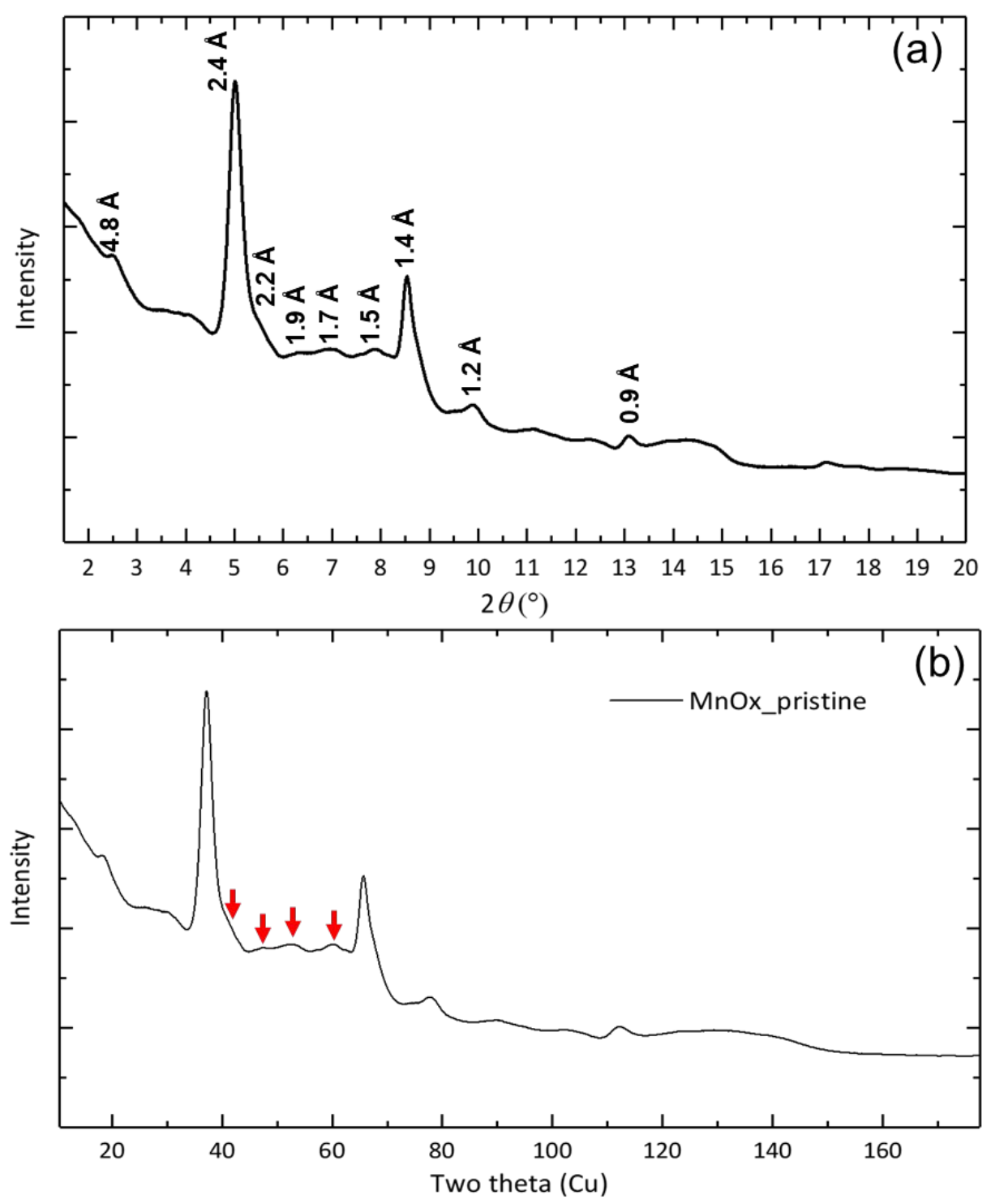

Figure S1. (a) Synchrotron XRD pattern of $\mathrm{MnO}_{\mathrm{x}}$ with $d$-spacings indicated for the main reflections. (b) X-ray diffraction pattern of pristine $\mathrm{MnO}_{\mathrm{x}}$, converted to the wavelength of $\mathrm{Cu} \mathrm{K}_{\alpha}$ for a more convenient comparison with the literature. Arrows with a red color indicate characteristic diffraction peaks of todorokite. 


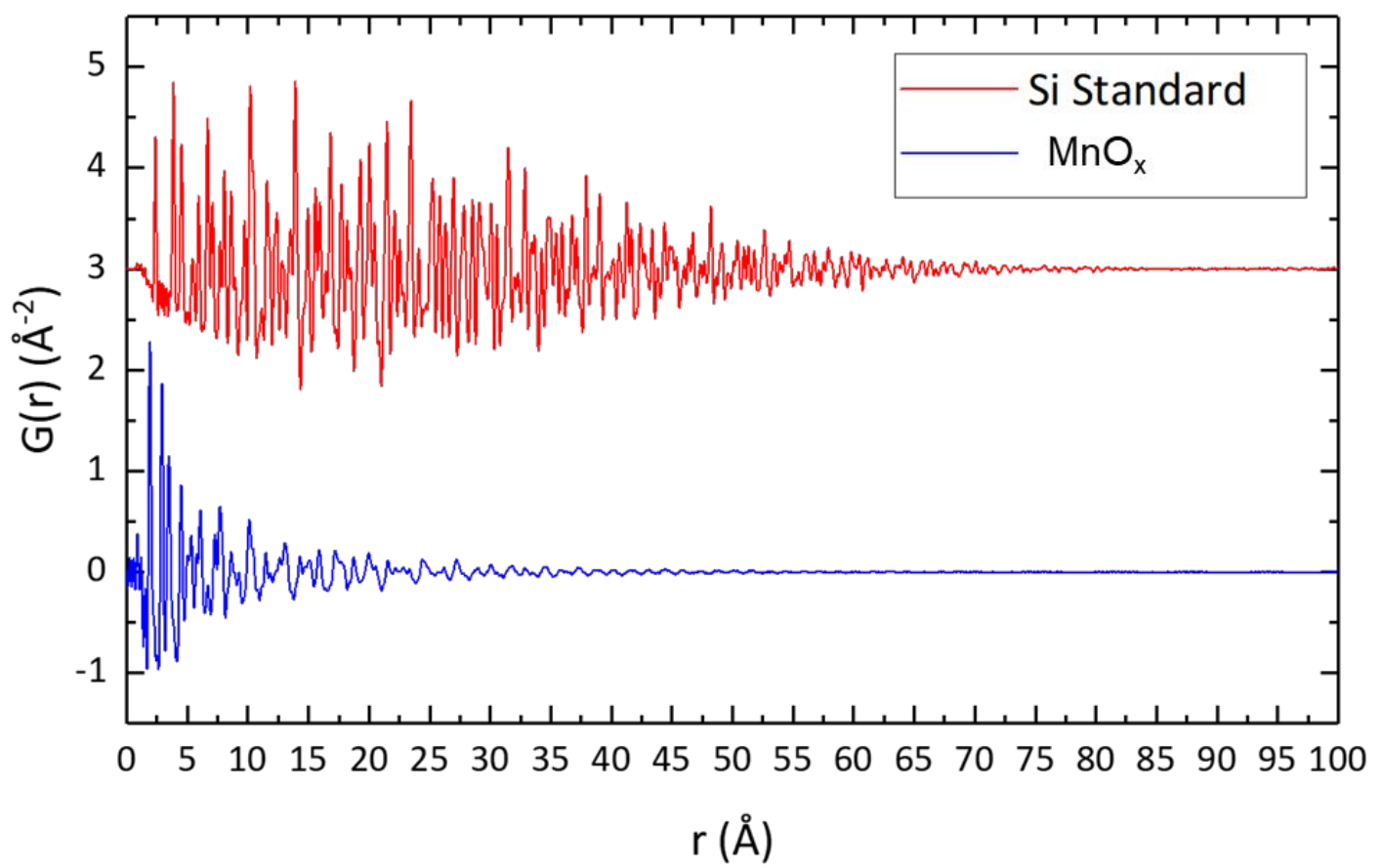

Figure S2. PDF of pristine $\mathrm{MnO}_{\mathrm{x}}$ and standard Si (NIST SRM 640f). 


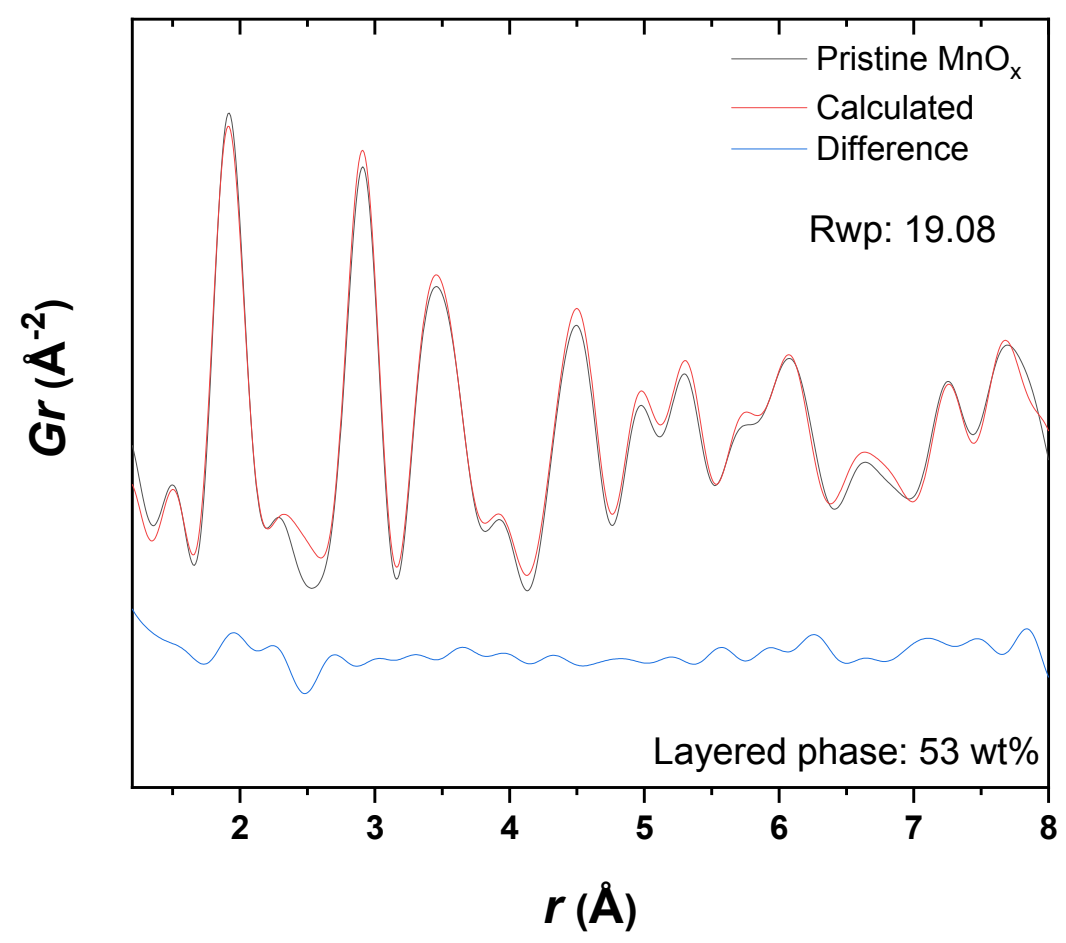

Figure S3. Fit of the PDF data for pristine $\mathrm{MnO}_{\mathrm{x}}$ using a mixture model of todorokite and layered $\mathrm{MnO}_{2}$. 


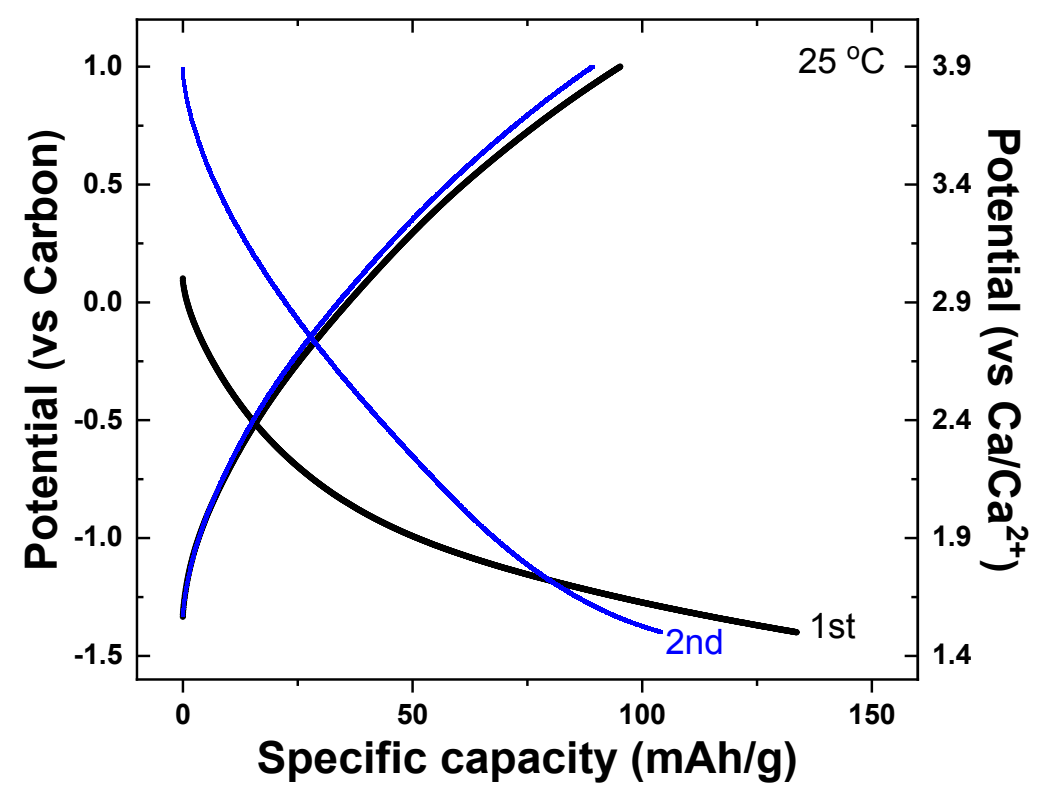

Figure S4. Potential versus capacity profiles of $\mathrm{MnO}_{\mathrm{x}}$ cycled in $0.5 \mathrm{M} \mathrm{Ca}(\mathrm{TFSI})_{2}$ dissolved in diglyme at $25^{\circ} \mathrm{C}$. (Black: $1^{\text {st }}$ cycle and blue: $2^{\text {nd }}$ cycle) 


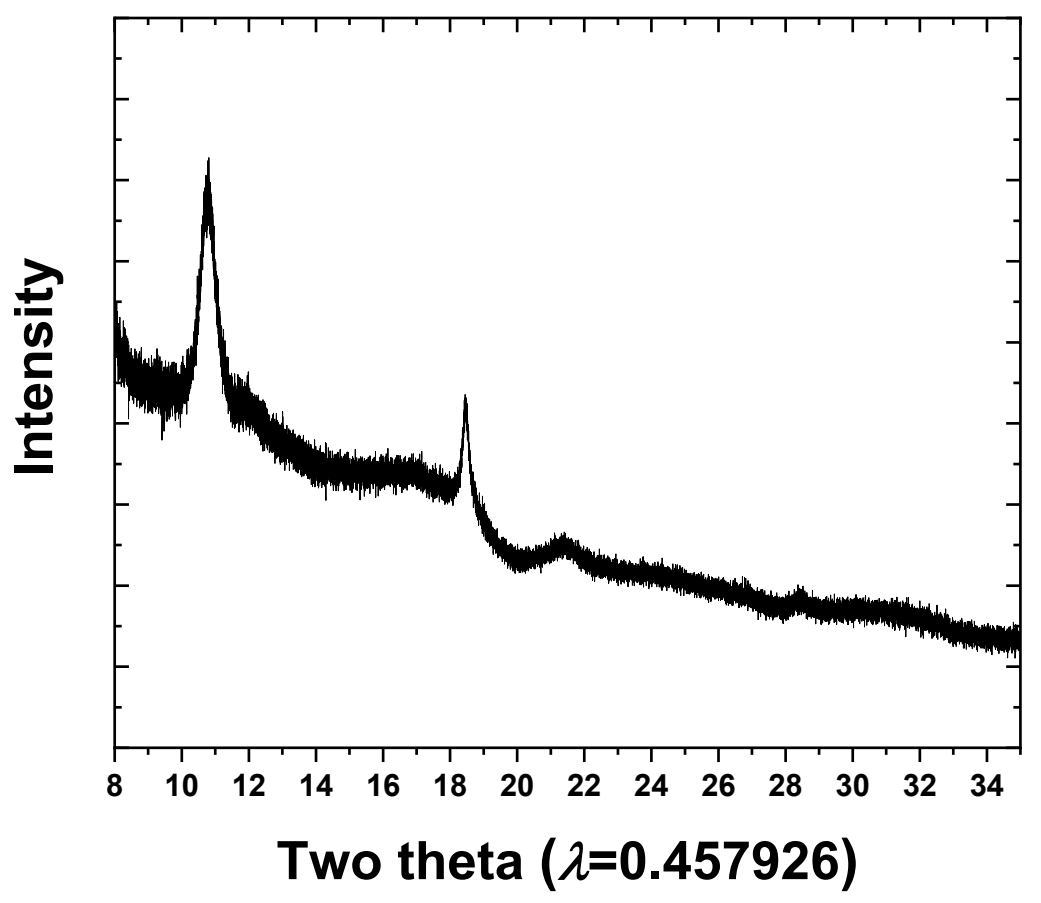

Figure S5. Synchrotron XRD pattern of the electrode after 100 cycles at room temperature. 


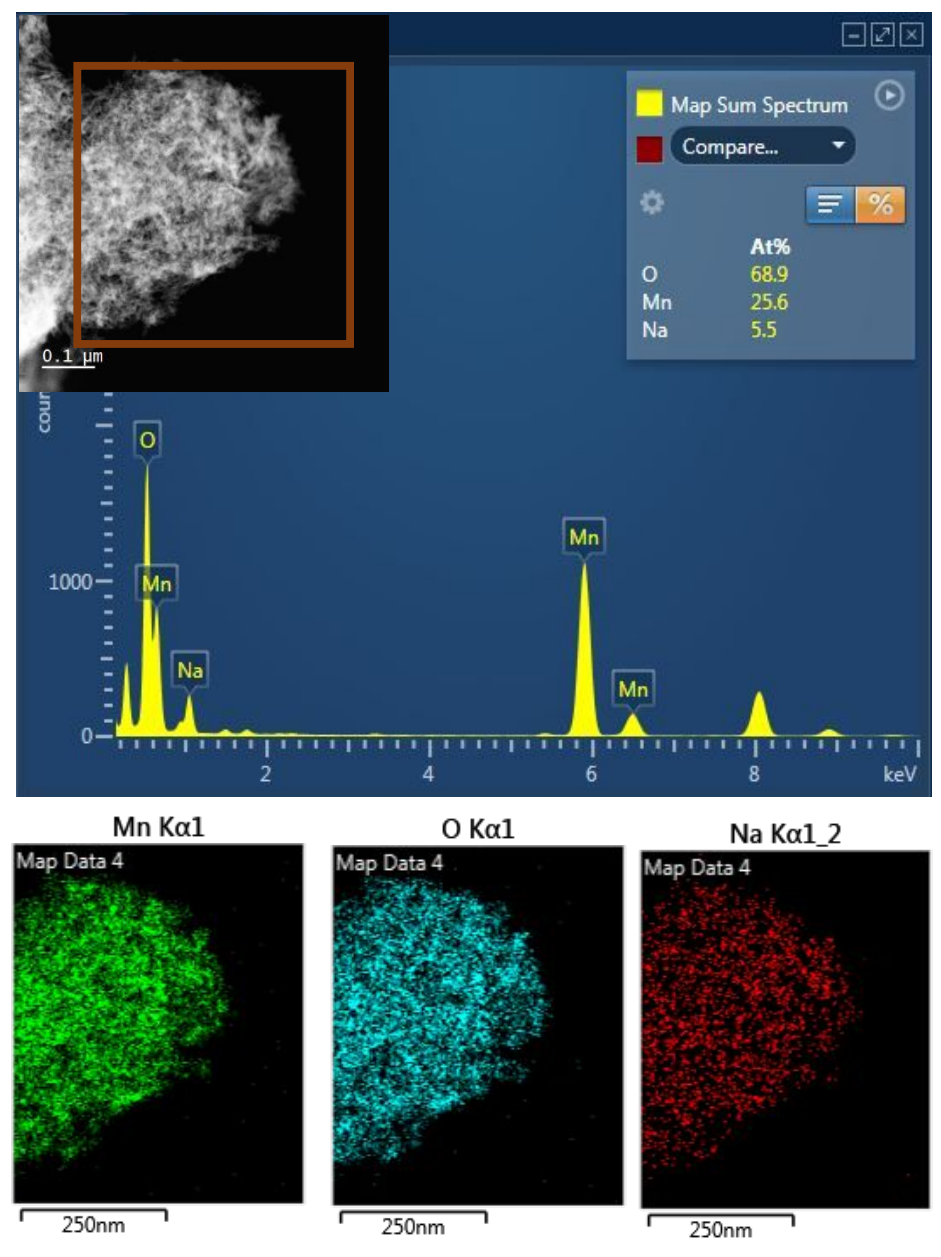

Figure S6. EDX mapping of pristine $\mathrm{MnO}_{\mathrm{x}}$ nanocrystals. 


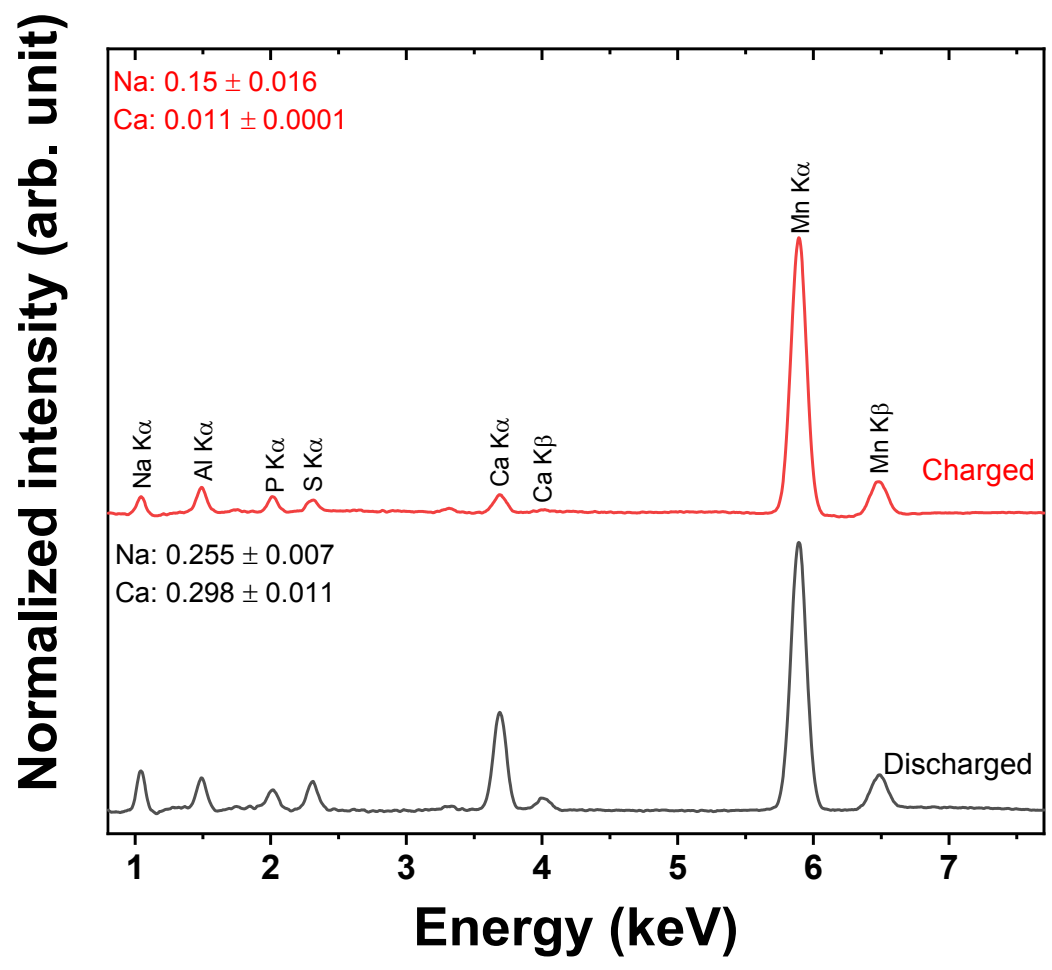

Figure S7. SEM-EDX of discharged and charged $\mathrm{MnO}_{\mathrm{x}}$. The values in the spectra were averaged by measuring multiple areas in the electrodes. 

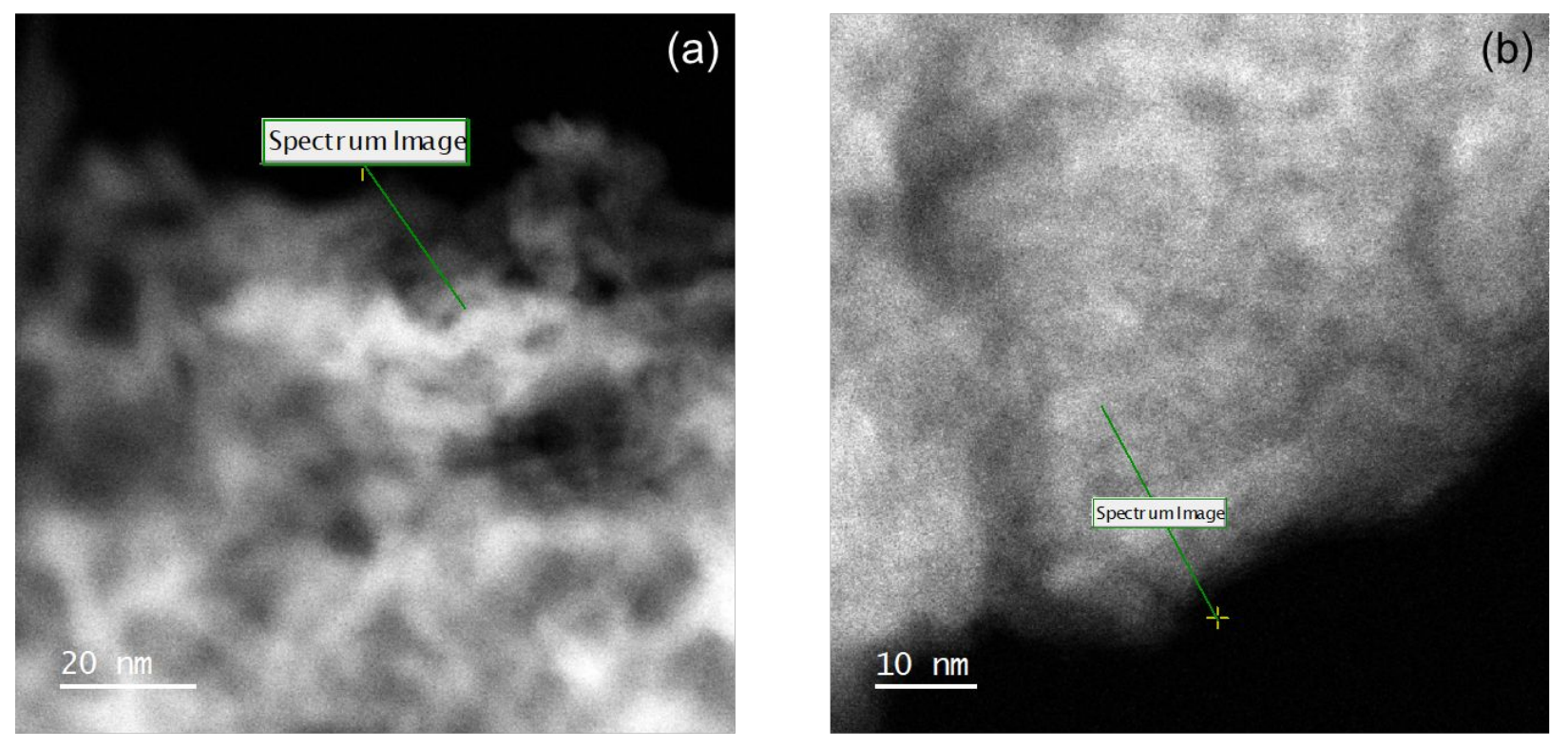

Figure S8. STEM images of (a) pristine and (b) discharged $\mathrm{MnO}_{\mathrm{x}}$ showing the locations where the spectra in Figure 2d were collected. 

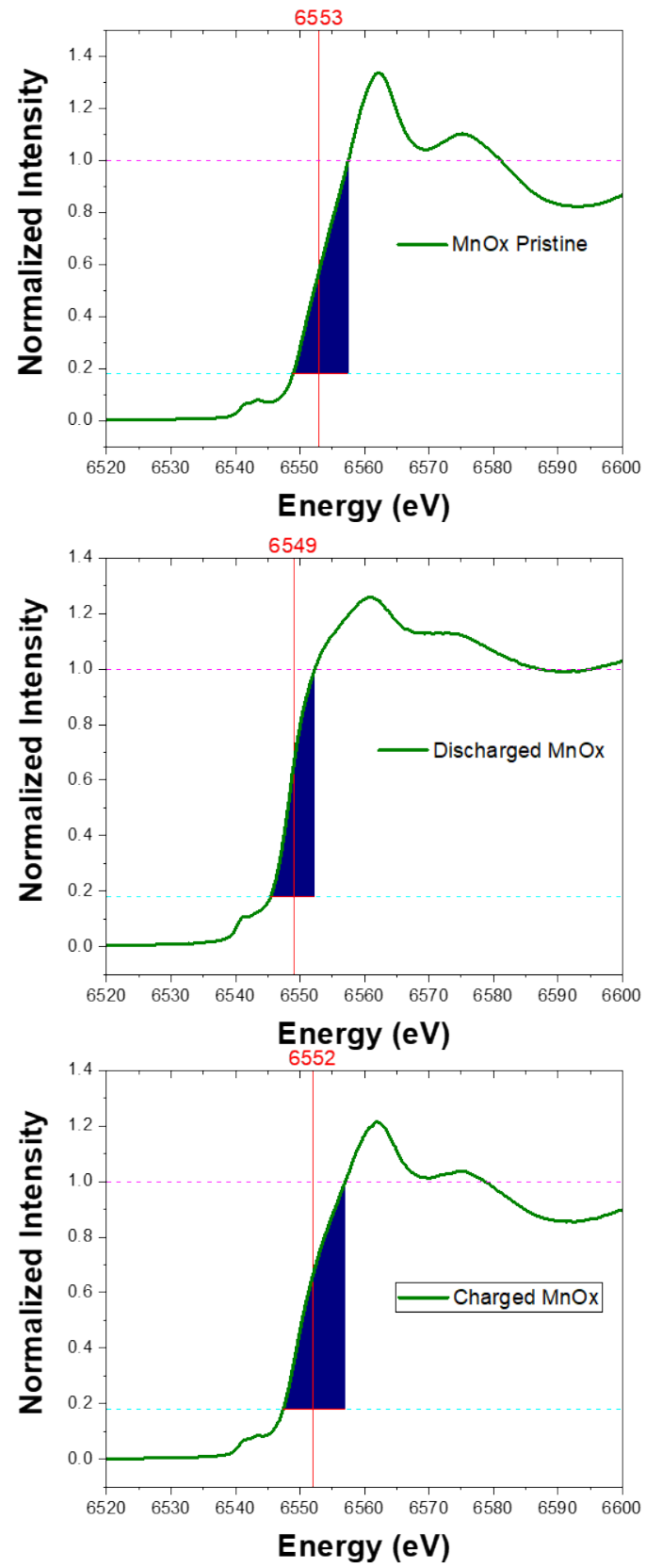

Figure S9. Plots depicting the procedure of integration used to extract the position of the Mn absorption edge for $\mathrm{MnO}_{\mathrm{x}}$ at different states of charge. Integration limits of inverse functions, $\mu_{1}$ (0.18) and $\mu_{2}(1.00)$, were applied to minimize contributions from the pre-edge features and reduce effect from strong whiteline. 
Table S1. Position of the $\mathrm{Mn} \mathrm{K}$ absorption edge for different states of $\mathrm{MnO}_{\mathrm{x}}$. Integration of the spectra according to Figure S9 was used to determine edge positions by following previous literature. ${ }^{[43]}$ A value of $\mu_{1}=0.18$ was applied to minimize contributions from the pre-edge features and $\mu_{2}=1.00$ was used to avoid interference from the strong whiteline.

\begin{tabular}{cc} 
& E edge \\
\hline Sample & Transmission $(\mathrm{eV})$ \\
\hline \hline Pristine & 6553 \\
Discharged & 6549 \\
Charged & 6552
\end{tabular}




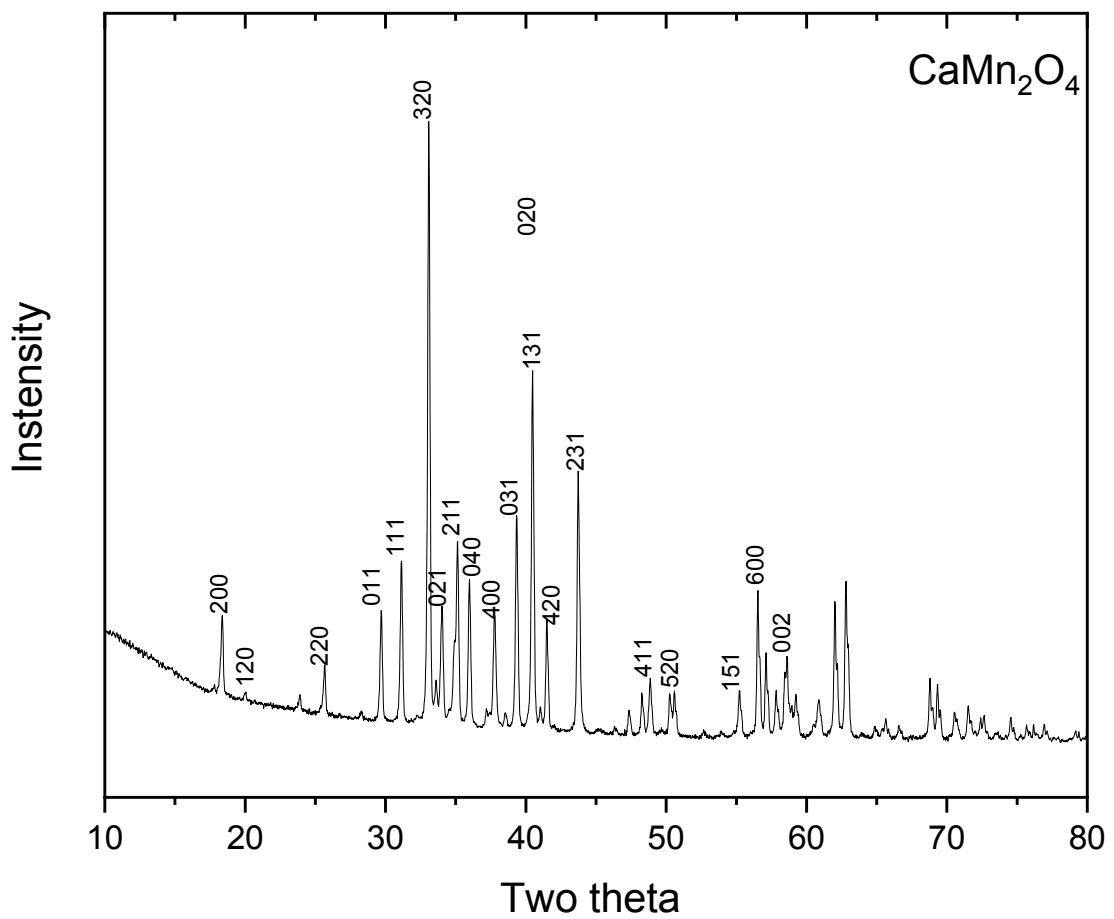

Figure S10. XRD pattern of synthetic $\mathrm{CaMn}_{2} \mathrm{O}_{4}$. 


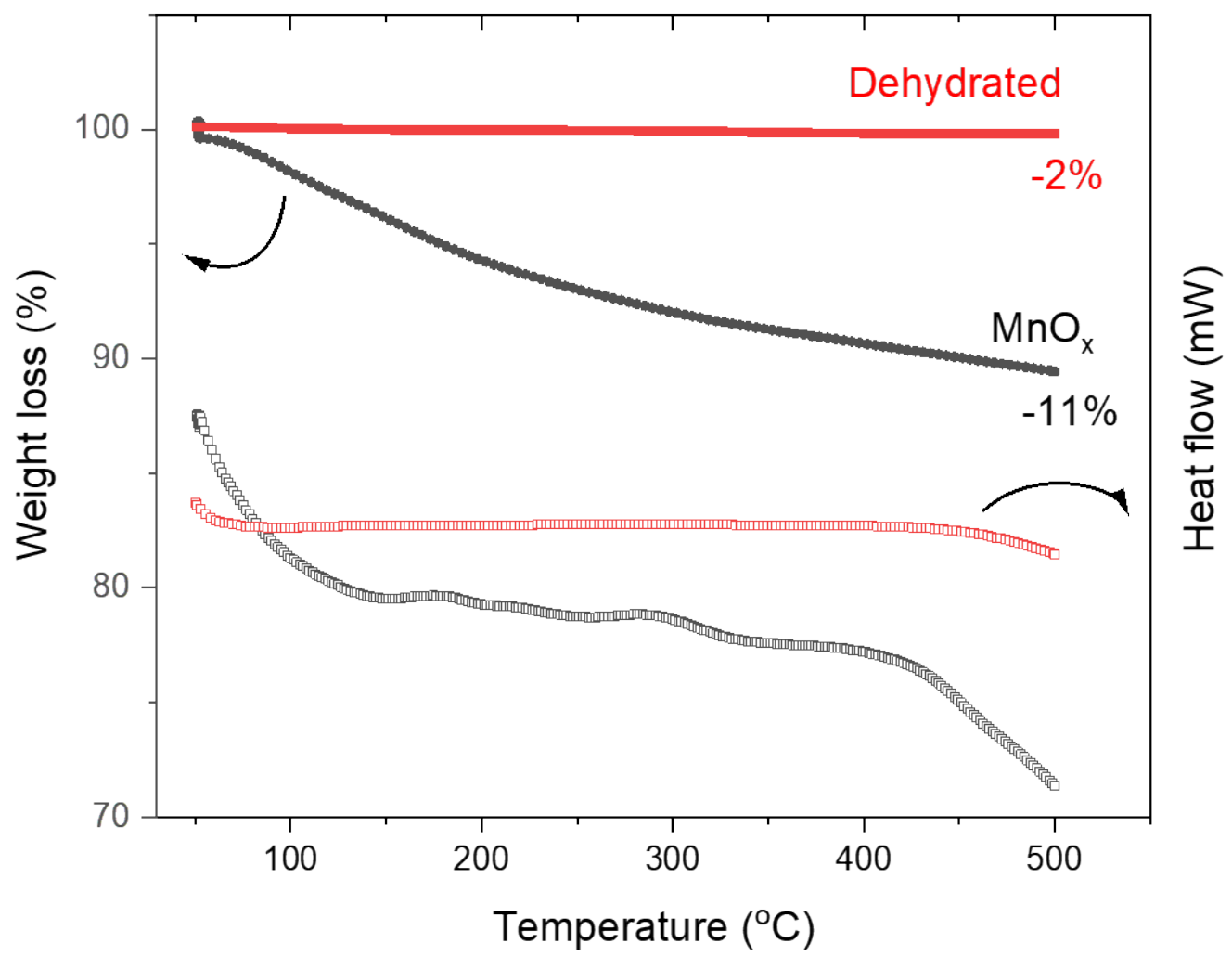

Figure S11. Thermal gravimetric analysis of as-made $\mathrm{MnO}_{\mathrm{x}}$ and dehydrated $\mathrm{MnO}_{\mathrm{x}}$. 

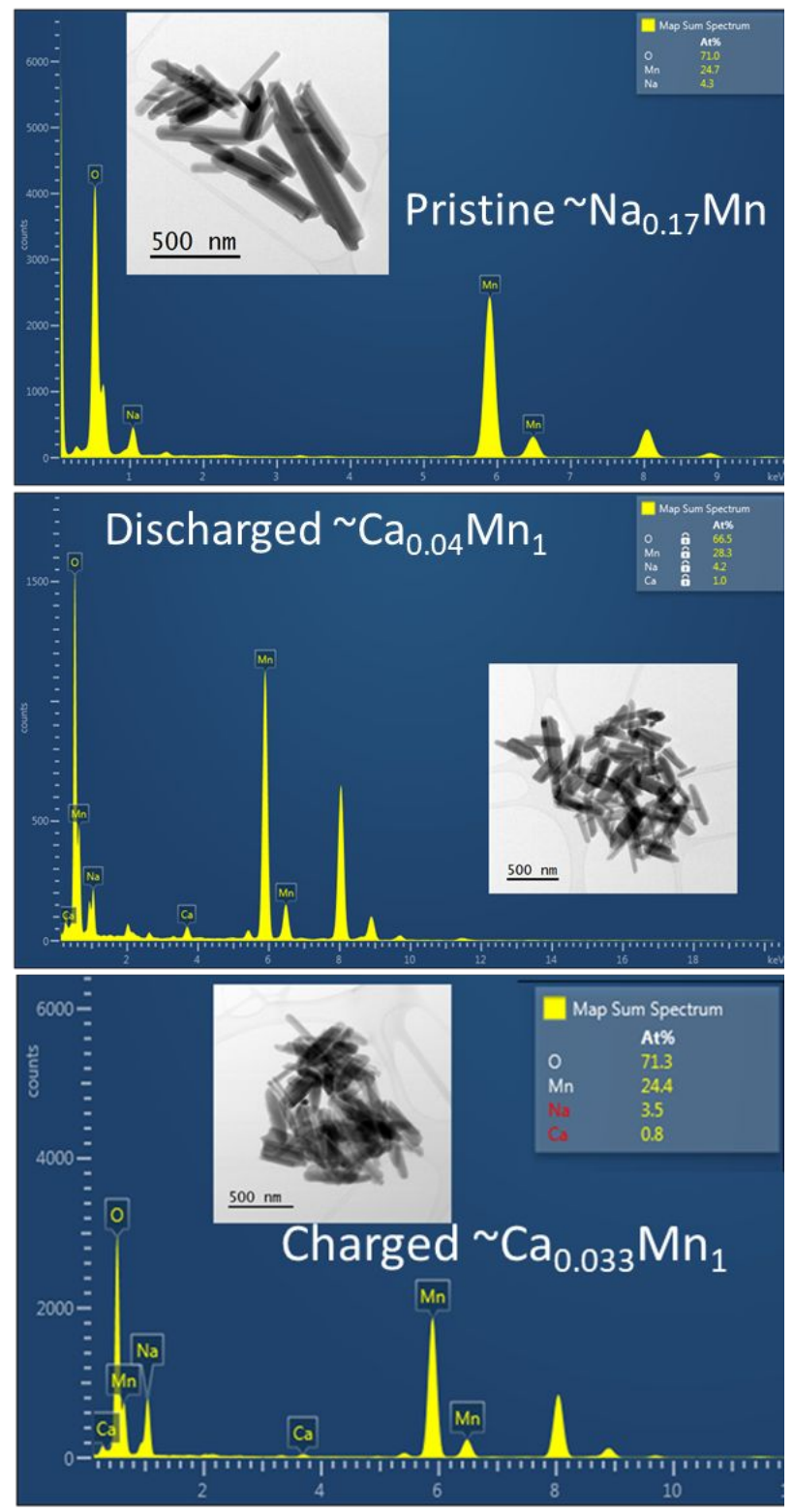

Figure S12. STEM-EDX of pristine, discharged and charged states of dehydrated $\mathrm{MnO}_{\mathrm{x}}$. 


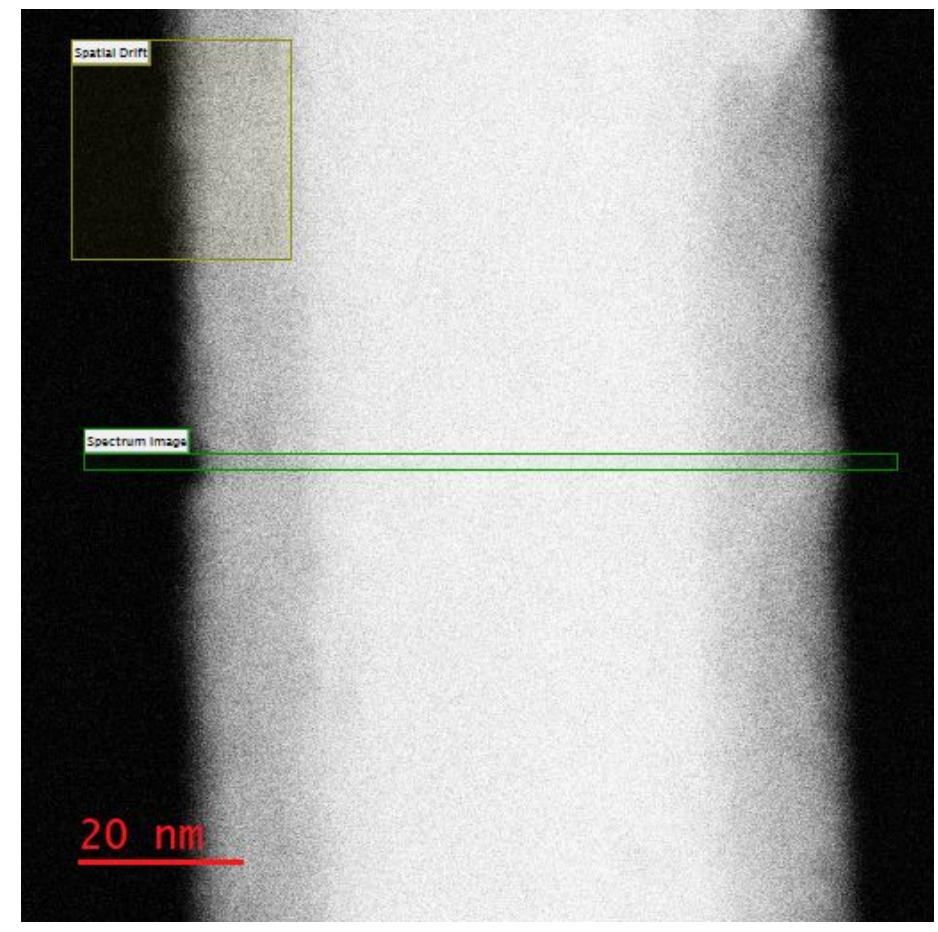

Figure S13. STEM images of discharged dehydrated $\mathrm{MnO}_{\mathrm{x}}$ showing the scans where the spectra in Figure 5c were collected. 